\title{
Leveraging media and health communication strategies to overcome the COVID-19 infodemic
}

\author{
Nour Mheidly ${ }^{1}$ (D) Jawad Fares ${ }^{2}$ (D)
}

Published online: 21 August 2020

(c) Springer Nature Limited 2020

\begin{abstract}
The COVID-19 pandemic has caused a complementary infodemic, whereby various outlets and digital media portals shared false information and unsourced recommendations on health. In addition, journals and authors published a mass of academic articles at a speed that suggests a non-existent or a non-rigorous peer review process. Such lapses can promote false information and adoption of health policies based on misleading data. Reliable information is vital for designing and implementing preventive measures and promoting health awareness in the fight against COVID-19. In the age of social media, information travels wide and fast, emphasizing a need for accurate data to be corroborated swiftly and for preventing misleading information from wide dissemination. Here, we discuss the implications of the COVID-19 infodemic and explore practical ways to leverage health communication strategies to overcome it. We propose the "Infodemic Response Checklist" as a comprehensive tool to overcome the challenges posed by the current and any future infodemics.
\end{abstract}

Keywords COVID-19 · Pandemic $\cdot$ Infodemic $\cdot$ Communication $\cdot$ Social media Science $\cdot$ Peer review $\cdot$ Infodemic Response Checklist

\section{Introduction}

Amid the immense rise of COVID-19 cases, deaths, and global spread of the disease, the Director-General of the World Health Organization (WHO) announced on 11 March 2020 that this viral disease has become a pandemic [1]. Health authorities around the world have confirmed cases from South East Asia, the Americas, Europe,

Electronic supplementary material The online version of this article (https://doi.org/10.1057/s4127 1-020-00247-w) contains supplementary material, which is available to authorized users.

Jawad Fares

jawad.fares@northwestern.edu

1 Faculty of Information, Lebanese University, Beirut, Lebanon

2 Northwestern University Feinberg School of Medicine, Chicago, IL 60611, USA

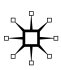


Eastern Mediterranean, Africa, and Western Pacific. Schools and workplaces shut down, borders between countries closed, and countries imposed travel restrictions as a precautionary safety measure to limit spread of the virus. Under such dire conditions, the public searches for information and guidance that helps them react in an evidence-based manner to the outbreak to limit viral transmission. Media, in various forms, becomes the primary source of information.

A surfeit of information about the COVID-19 pandemic spread widely. While some information was true, much was false. This resulted in an 'infodemic,' whereby waves of misinformation and rumors on the pandemic interfered with quelling it.

The COVID-19 infodemic did not come as a surprise. In 2018, Heidi Larson predicted that the impact of the next major outbreak would be magnified by emotional contagion that would be digitally enabled [3]. She based her prediction on epidemiological studies showing that confidence in vaccines decreased between 2015 and 2018 [4, 5]. Although misinformation has spread across history, social media and technological advances in communication amplify its impact. Previous studies show that through social media, people share falsehoods far more than evidencebased information [6-8]. A two-day analysis of 1000 tweets circulated on Twitter (published on 6 and 7 February 2020) showed false information to have been tweeted more than science-based evidence or fact-checking tweets [9]. Knowing that science-based evidence is vital to ensure the public is well informed and can react effectively to a pandemic, an infodemic clearly hinders mitigation, conveys misleading messages on the disease, and promotes ineffective precautionary measures. Thus, it is essential for us to address and counter infodemics to quell COVID-19.

Despite a late response to the pandemic in China, an analysis of Chinese newspapers, social media content, and other digital platform data, found that a unique combination of strong governance, strict regulation, strong community vigilance and citizen participation, and wise use of big data and digital technologies were key factors in China's efforts to combat this virus [10]. In this Viewpoint, we describe the COVID-19 infodemic and its implications, discuss the role of media in health promotion, and explore practical ways to leverage health communication strategies to overcome the current and any future infodemic.

\section{Role of media in health promotion}

Media is a powerful avenue for the dissemination of wellness education [11]. It plays a fundamental role in the public response to a pandemic, as it serves as a portal for communication between governments, health institutions, and people. The 'invisible' nature of pandemics dictates an important role for media as the "eye" of the public. Media channels become windows through which the public looks for accurate information, scientific sound facts, government decisions, and reactions of the general public. Input that people collect as 'receivers' shape their actions and reactions to the pandemic.

Media also contributes substantially to health awareness and promotion, making it an essential mediator for health communication. It plays an important role in changing attitudes and intentions, and in influencing health behavior. 'Health 
communication' is a broad term, defined as the study or use of communication techniques to improve the health sector [12]. Media's effectiveness in health communication lies in strong written, verbal, and visual communication strategies that can impact public views and perceptions [2].

\section{Media coverage of the COVID-19 pandemic}

Since the outbreak of the virus, international and local news networks promoted awareness and decreased anxiety among the public through live coverage of news briefings, press conferences, and town halls. Health officials and many others posted and explained health guidelines and governmental instructions on websites, in journals, magazines, and on social media platforms including Facebook, Instagram, and Twitter.

In the age of social media dominance, monitoring all published posts related to the pandemic poses a difficult challenge. The phenomenon of spreading misinformation during outbreaks has been known to occur since the Middle Ages [13]. However, social media amplify it considerably. Unverified sources posting on platforms play central roles in reporting incorrect numbers of cases and inaccurate guidelines, and advertising unapproved treatments and remedies as antiviral cures. Such misinformation led to an increase in public anxiety about health, and resulted in chaos, fraudulent schemes, financial abuse, and fear. In the United States, for example, promoters of misinformation sent text messages in the early stages of the outbreak about lockdowns, upcoming governmental regulations, and economic collapse, spreading their messages widely through the population [14]. The National Security Council acted to clarify which circulating text messages were false, to reduce fear and panic among residents [14]. Claims that drinking hot water, snake oil, or silver, and burning incense leaves would cure coronavirus became popular [15]. Advertisements run by Amazon for protective masks spiked prices and increased hoarding of medical equipment, in times when the medical community worldwide was in dire need of supplies [16]. Many social media accounts fueled conspiracy theories about COVID-19 as a biological weapon and directed readers and viewers to buy vitamins and other products from stores [17]. Posts that falsely linked 5G, a wireless communication technology that supports cellular data networks, to COVID-19 also spread widely [18]. Anti-vaccine movements exploited the outbreak, using social media accounts opposing vaccines to lure a surge in views and followers [19].

The Director-General of the WHO called the phenomenon an 'infodemic.' He explained that fake news spread faster and more easily than the virus, and is just as dangerous [20]. The WHO later made an announcement that it would be working closely with social media platforms and search engine companies like Facebook, Google, Pinterest, Tencent, Twitter, TikTok, YouTube, among others, to deter the spread of rumors and misinformation. 


\section{Science-based communication during the COVID-19 pandemic}

In times of pandemics, speeding scientific data to the public can be beneficial-when it is accurate. Misleading scientific data can worsen the pandemic by promoting ineffective or harmful policies or by encouraging dangerous conduct, or both. In comparison with previous pandemics, researchers and health professionals published much more about COVID-19 in the early phase of the academic response than during the 2003 SARS outbreak [21].

Preprints gained increased popularity. Researchers promptly posted their findings online without peer review or editorial validation, using servers such as bioRxiv and medRxiv. Several preprints shared quickly and widely on social media then appeared on live broadcasts by news outlets.

Although preprints are becoming more acceptable in academic publishing, they remain works-in-progress. Policymakers should not consider them to be evidence-based science nor use them as the basis for public health decisions, as preprints have not undergone a rigorous process of peer review [22, 23]. Often, research that emerges from review is a much refined and a more robust version of the initial submission. For example, observational studies reporting that the drug 'hydroxychloroquine' is linked to severe adverse events and mortality among patients with COVID-19 were found to be based on unsourced data, and the papers had to be retracted $[24,25]$.

\section{Response and implications}

There has been a notable and global response to the COVID-19 infodemic by international organizations, governments, social media technology companies, and major science bodies. The United Nations (UN) responded to the infodemic by forming a UN Coronavirus (COVID-19) portal for public access to reliable and up-to-date information [26]. The UN Office of Drugs and Crime published materials to promote cybersecurity to protect children from possible online abuse and hospitals from disruptive cyberattacks. The UN Office of Information and Communications Technology conducted webinars on online safety for those conducting work remotely, away from their usual and more secure worksites. The WHO also launched a portal called "myth busters" to expose false data [27]. Its designers arrange for each 'busted myth' to appear with its associated fact in a catchy infographic that can be freely downloaded and shared on social media platforms. The WHO's risk communication team established the WHO Information Network for Epidemics to share health information with specific target groups [13]. The United States Centers for Disease Control and Prevention (CDC) built a website for COVID-19-related updates and news. One page begins "Stop the Spread of Rumors: Know the facts about coronavirus disease" then emphasizes five clear points for coping with COVID-19 in daily life [28]. 
Governments worldwide responded to both the pandemic and the infodemic. The policy tracker of the International Monetary Fund reported that 193 countries took economic measures and adopted policy changes in response to the pandemic [29]. In addition to public health strategies to minimize the spread of the virus, such as enforcing lockdowns and promoting social distancing norms, government officials offered daily or weekly briefings to their constituents with major news channels covering these events live 'on air.' The officials usually related the number of cases and updated the public on the infection and its control, presenting facts and effective measures. Officials also engaged the public through social media. Twitter, specifically, proved to be a powerful tool for sharing health information. A content analysis of Twitter usage by Group of Seven (G7) world leaders in response to COVID-19 revealed that $82.8 \%$ of their COVID-19-related tweets were informative, $9.4 \%$ were morale-boosting, and $6.9 \%$ were political [30].

Social media technology executives grasped the severity of the situation. Google established a campaign that provides preventive tips to the public to help slow down viral spread and authenticates information about COVID-19 spreading on its platform [31]. Google also created an 'SOS Alert' on COVID-19 in many languages and exerted efforts to assure that WHO and its social media accounts would be the first sources of information the public would see when using the Google search engine [13]. Amazon restricted and removed advertisements with false claims about protective equipment offered for sale [32]. Facebook, YouTube, Microsoft, and Twitter announced implementation of further restrictions on published content related to the pandemic and their intent to remove medically disproved claims [33, 34].

Scientific and medical bodies acted to promote science-based knowledge on COVID-19. Medical and scientific journals took steps to ensure timely dissemination of scientific data. Journals and publishing companies formed resource centers on their websites to address COVID-19-related published material. Participants included major scientific journals (Nature and Science) and respected medical journals (the New England Journal of Medicine, JAMA, the BMJ, as well as the Lancet journals) along with respected publishing bodies, including Elsevier, Springer, Oxford, and Wiley. Journals arranged for speeding peer review ('fast-tracking') to support prompt public health policymaking and benefit healthcare workers and the public with new discoveries and clinical trial results. Many publishers adopted open-access publication policies for material related to the pandemic to ease access to science-based evidence. Preprint server bioRxiv added a yellow banner to label all articles related to COVID-19, and to remind readers that papers posted there are preliminary reports, not articles having undergone peer review. This warned readers that the findings should not be judged as conclusive nor reported as established data.

\section{What else can be done: recommendations}

Still, more can be done. We propose a 12-item Infodemic Response Checklist (IRC) as a comprehensive tool to overcome the challenges posed by infodemics (Supplemental Fig. 1). Officials responsible for health communication strategies and media 
policies can adopt several measures to overcome the COVID-19 infodemic, communicate valid information, and protect the global community against any future info/ pandemics.

1. Provide more exposure and airtime for medical professionals, scientists, and public health personnel to provide authentic, useful, and transparent information for the public.

Direct and effective communication between scientists and the public on global concerns is essential to allay fear and prevent erroneous assumptions. While the role of scientific journals and institutions is important for dissemination of evidence-based science, scientists and medical professionals are uniquely positioned to empower people with facts through interviews, op-eds, podcasts, blogs, and social media [35]. CNN and Facebook, for example, collaborated to host a global town hall during the outbreak, during which medical doctors and psychologists participated from the studio or via skype to answer people's questions. Dr. Anthony Fauci, director of the National Institute of Allergy and Infectious Diseases in the United States, has taken a leading role in the White House Coronavirus Task Force, participating in interviews, town hall meetings, and engaging journalists in person during daily press briefings.

2. Promote websites of public health organizations via search engines.

Engines like Google and Yahoo must promote websites of official public health organizations to those seeking information on preventive measures on the internet. A recent study assessing health information about COVID-19 prevention on the internet revealed substantial differences regarding recommendations to wear masks or wash hands among websites of different countries affected by COVID19 [36]. Searches of keywords that relate to the infodemic must prioritize public health websites and list them prominently where viewers will see them at the start of a search.

3. Verify the accounts of public health personnel on popular social media platforms.

Media platforms like Twitter and Facebook, where the public indulges heavily in social interaction must verify the accounts of those appearing to be medical professionals. This will make it easier for the public to know whether the claimed source is verified and authentic or not.

4. Promote the posts of public health and medical professionals.

In times of crises, social media platforms can sponsor posts of health officers to make sure that the public exposure and understanding is guided by reliable sources and authentic information.

5. Monitor engagement on social media platforms to control the messages being delivered.

During the Zika virus outbreak in 2016, a cross-sectional survey of public information officers at local public health departments across the United States revealed that monitoring social media resulted in higher satisfaction with crisis management [37]. Thus, social media technology companies must closely review content shared on their platforms during pandemics to ensure false information does not promote harmful perceptions or practices. 
6. Establish programs that help people cope with stress and address their mental health concerns.

The media has a huge role to play in addressing the mental health aspect of the pandemic. Sick individuals may suffer from stress, anxiety, and fear. Quarantine and self-isolation may have severe psychological consequences and lead to difficulties in concentration, increased intake of alcohol, tobacco, and other drugs [38]. Lack of public knowledge on the virus can promote social stigma against individuals infected or suspected to be infected by the virus [39]. Furthermore, closure of medical clinics and postponement of medical appointments and elective procedures can worsen chronic health conditions. Acknowledging these conditions and guiding the public on how to manage and contain them via broadcasting media programs or social media posts is essential to promote health and well-being.

7. Adopt an empathic style of communication to grab public attention and address health concerns.

Empathy in communication is critical for managing public anxiety and promoting behavioral compliance with public health guidelines. In China, online users generally had low engagement with posts relevant to COVID-19 from government agencies. Public posts that attracted more engagement, were more personal, showed empathy to affected people, and expressed worry about the epidemic [40]. Merely sharing updated information and policies may be insufficient to capture public interest in official communications.

8. Promote dialogue to understand people's perceptions and the motives behind their practices.

Communication through town hall meetings and debate circles can address concerns raised and hesitancy to adhere to health measures [3]. Such communication can further strengthen societal adhesion and unity.

9. Share personal experiences on social media to combat misinformation.

Promoting stories of people who have been affected by the disease can have a major impact on people's perception of the pandemic. To increase public confidence in HPV vaccines, Danish public health officials emphasized the risk of disease and promoted stories about people who had lost wives and mothers to cervical cancer. Ireland's social media efforts used similar tactics to rebuild HPV-vaccine confidence; numbers for 2018 showed an increase of $6 \%$ for vaccine uptake from 2017 [41]. Adopting a similar strategy for COVID-19 is important.

10. Direct health communication strategies towards minority populations and people of different classes, races, and ethnicities.

In the United States, health professionals estimated that about a third of COVID19 fatalities are African Americans, even though African Americans constituted only $14 \%$ percent of the COVID-19 cases $[42,43]$. Based on media reporting, in New York, African Americans died at twice the rate of their white peers; Latinos in the city were also falling to the virus at a much higher rate than white or Asian New Yorkers [42]. Media companies must design health awareness campaigns for influencers and role models of different racial and ethnic backgrounds to present to the public. This ensures that people who share similar race or eth- 
nicity feel relevant and thus become aware of the reality of the pandemic and the importance of prevention strategies and governmental efforts. In addition, governments and health officials need to direct health communication campaigns at highlighting the lack of access to healthcare facilities and services that certain populations might suffer from to drive corrective governmental health policies.

11. Develop educational material and speed the share of evidence-based science to address existing wrong perceptions, correct behaviors, and promote healthy practices.

During outbreaks, people struggle with uncertainty and look for sources to fill their needs for information. Unfortunately, ordinary citizens and communication systems do not operate at the same pace as the scientific method, which often takes time to provide evidence-based results. As such, false information that are usually marginally believable lead to wrong conclusions and fake news reports [34]. Public health officials need to be faster in filling the public void for information and in directing conventional and social media platforms to better comprehend what to be reported and how data should be portrayed. When conventional media provides evidence-based information to the general public, it will eventually be picked up on social media [13], which will facilitate its rapid widespread among the public. This will ensure that the people will act effectively to control the disease and mitigate its impact. Awareness campaigns do not always achieve their desired impact because public health officials craft messages based on what they want to promote, without addressing existing perceptions.

12. Increase investment in the research and development of health communication to explore and understand strategic ways of targeting different populations.

Health communication is a rising field in different parts of the world [12, 44]. Investing in the field is important to understand the psychological influences that affect the individual efforts in following guidelines and seeking the right information. In addition, more research will be important to learn which health communication strategies will prove effective-through trials that assess communal perceptions of health communication and awareness campaigns.

\section{Conclusion}

Infodemics are as serious as pandemics. International bodies, governments, and health professionals must identify the overflow of contradictory news, misinformation, and manipulated data on social media as a global public health threat. The current COVID-19 outbreak is an example of how hard it is to handle emerging infectious diseases. While speed is the enemy of rigorous science, the perfect scenario for facing an infodemic involves disseminating evidence-based and reliable information swiftly and widely among the public. Media, through its various forms and portals, can play a vital role in raising social awareness, increasing exposure to truthful information, promoting healthy habits, and improving psychological well-being. Governments should develop and direct public health policies to address the role of media portals in propagating information in times of 
pandemics. The Infodemic Response Checklist is a novel tool for promoting more efficient health communication strategies to alleviate the effects of the current outbreak of misinformation and any other outbreaks that may arise in the future.

\section{Compliance with ethical standards}

Conflict of interest The authors declare that they have no conflict of interest.

\section{References}

1. World Health Organization. WHO Director-General's opening remarks at the media briefing on COVID-19-11 March 2020. 2020. https://www.who.int/dg/speeches/detail/who-director-gener al-s-opening-remarks-at-the-media-briefing-on-covid-19-11-march-2020.

2. Centers for Disease Control and Prevention. World Map: Global Map. 2020. https://www.cdc. gov/coronavirus/2019-ncov/cases-updates/world-map.html.

3. Larson HJ. The biggest pandemic risk? Viral misinformation. Nature. 2018;562(7726):309-10.

4. Larson HJ, De Figueiredo A, Xiahong Z, Schulz WS, Verger P, Johnston IG, Cook AR, Jones NS. The state of vaccine confidence 2016: global insights through a 67-country survey. EBioMedicine. 2016;12:295-301.

5. Larson HJ, Hartigan-Go K, de Figueiredo A. Vaccine confidence plummets in the Philippines following dengue vaccine scare: why it matters to pandemic preparedness. Hum Vaccines Immunother. 2019;15(3):625-7.

6. Lewandowsky S, Ecker UK, Seifert CM, Schwarz N, Cook J. Misinformation and its correction: Continued influence and successful debiasing. Psychol Sci Public Interest. 2012;13(3):106-31.

7. Lazer DM, Baum MA, Benkler Y, Berinsky AJ, Greenhill KM, Menczer F, Metzger MJ, Nyhan B, Pennycook G, Rothschild D, Schudson M. The science of fake news. Science. 2018;359(6380):1094-6.

8. Del Vicario M, Bessi A, Zollo F, Petroni F, Scala A, Caldarelli G, Stanley HE, Quattrociocchi W. The spreading of misinformation online. Proc Natl Acad Sci USA. 2016;113(3):554-9.

9. Pulido CM, Villarejo-Carballido B, Redondo-Sama G, Gómez A. COVID-19 infodemic: More retweets for science-based information on coronavirus than for false information. Int Sociol. 2020:0268580920914755.

10. Hua J, Shaw R. Corona virus (Covid-19)“infodemic" and emerging issues through a data lens: the case of china. Int J Environ Res Public Health. 2020;17(7):2309.

11. Thomas J, Peterson GM, Walker E, Christenson JK, Cowley M, Kosari S, Baby KE, Naunton M. Fake news: medicines misinformation by the media. Clin Pharmacol Ther. 2018;104(6):1059-61.

12. Mheidly N, Fares J. Health communication research in the Arab world: a bibliometric analysis. Integr Healthcare J. 2020;2:e000011.

13. Zarocostas J. How to fight an infodemic. Lancet. 2020;395:676.

14. Collins B. False coronavirus rumors surge in 'hidden viral' text messages. NBC News. 2020. https ://www.nbcnews.com/tech/tech-news/false-coronavirus-rumors-surge-hidden-viral-text-messagesn1160936.

15. Brewster T. Coronavirus 'Cure' Claims Get FTC Warning, So Maybe Don't Drink Silver. Forbes. 2020. https://www.forbes.com/sites/thomasbrewster/2020/03/09/teas-essential-oils-and-drinkingsilver-ftc-warns-about-dubious-coronavirus-cures/\#3da43f2e1cba.

16. Palmer A. Amazon removes hundreds of thousands of 'high-priced offers' amid coronavirus price gouging. CNBC. 2020. https://www.cnbc.com/2020/03/06/amazon-removes-530000-productsamid-coronavirus-price-gouging.html.

17. Marantz A. Alex Jones's Bogus Coronavirus Cures. The New Yorker. 2020. https://www.newyorker. com/magazine/2020/04/06/alex-jones-bogus-coronavirus-cures. 
18. O'Donnell B. Here's why 5G and coronavirus are not connected. USA Today. 2020. https:// www.usatoday.com/story/tech/columnist/2020/03/21/did-5-g-cause-coronavirus-covid-19-pande $\mathrm{mic} / 2873731001 /$.

19. World Health Organization. Munich Security Conference. 2020. https://www.who.int/dg/speeches/ detail/munich-security-conference.

20. Pichai S. COVID-19: How we're continuing to help. Google's response to COVID-19. 2020. https:// blog.google/inside-google/company-announcements/covid-19-how-were-continuing-to-help/.

21. Sharma M, Scarr S, Kelland K. Speed Science. 2020. https://graphics.reuters.com/CHINA-HEALT H-RESEARCH/0100B5ES3MG/index.html.

22. Oransky I, Marcus A. Quick retraction of a faulty coronavirus paper was a good moment for science. 2020. https://www.statnews.com/2020/02/03/retraction-faulty-coronavirus-paper-good-moment-forscience/.

23. Marcus A, Oransky I. The Science of This Pandemic Is Moving at Dangerous Speeds. 2020. https:// www.wired.com/story/the-science-of-this-pandemic-is-moving-at-dangerous-speeds/.

24. Mehra MR, Desai SS, Kuy S, Henry TD, Patel AN. Retraction: cardiovascular disease, drug therapy, and mortality in Covid-19. N Engl J Med. 2020;382:2582. https://doi.org/10.1056/NEJMo a2007621.

25. Mehra MR, Desaii SS, Ruschitzka F, Patel AN. RETRACTED: hydroxychloroquine or chloroquine with or without a macrolide for treatment of COVID-19: a multinational registry analysis. Lancet. 2020. https://doi.org/10.1016/S0140-6736(20)31180-6.

26. United Nations. UN tackles 'infodemic' of misinformation and cybercrime in COVID-19 crisis. 2020. https://www.un.org/en/un-coronavirus-communications-team/un-tackling-\%E2\%80\%98inf odemic\%E2\%80\%99-misinformation-and-cybercrime-covid-19.

27. World Health Organization. Coronavirus disease (COVID-19) advice for the public: Myth busters. 2020. https://www.who.int/emergencies/diseases/novel-coronavirus-2019/advice-for-public/mythbusters..

28. Centers for Disease Control and Prevention. Stop the Spread of Rumors. 2020. https://www.cdc.gov/ coronavirus/2019-ncov/daily-life-coping/share-facts.html.

29. International Monetary Fund. Policy Tracker. 2020. https://www.imf.org/en/Topics/imf-and-covid 19/Policy-Responses-to-COVID-19.

30. Rufai SR, Bunce C. World leaders' usage of Twitter in response to the COVID-19 pandemic: a content analysis. J Public Health (Oxf). 2020. In press.

31. Scott M. Facebook's private groups are abuzz with coronavirus fake news. Politico. 2020. https:// www.politico.eu/article/facebook-misinformation-fake-news-coronavirus-covid19/.

32. Valinsky J. Amazon deleted 1 million items for price gouging or false advertising about coronavirus. CNN Business. 2020. https://www.cnn.com/2020/03/02/tech/amazon-coronavirus-products/ index.html.

33. Porter T. Twitter deleted a tweet by Rudy Giuliani for spreading coronavirus misinformation. Business Insider. 2020. https://www.businessinsider.com/coronavirus-twitter-deletes-giuliani-tweet-forspreading-misinformation-2020-3.

34. Warzel C. What we pretend to know about the coronavirus could kill us. The New York Times. 2020. https://www.nytimes.com/2020/04/03/opinion/sunday/coronavirus-fake-news.html.

35. Sholts S. Accurate science communication is key in the fight against COVID-19. 2020. https://www. weforum.org/agenda/2020/03/science-communication-covid-coronavirus.

36. Hernández-García I, Giménez-Júlvez T. Assessment of Health Information About COVID-19 prevention on the internet: infodemiological study. JMIR Public Health Surveill. 2020;6:e18717.

37. Avery EJ. Public information officers' social media monitoring during the Zika virus crisis, a global health threat surrounded by public uncertainty. Public Relat Rev. 2017;43(3):468-76.

38. Centers for Disease Control and Prevention. Manage anxiety \& stress. 2020. https://www.cdc.gov/ coronavirus/2019-ncov/prepare/managing-stress-anxiety.html.

39. Mansour A, Atoui R, Kanso K, et al. First Case of an Infant with COVID-19 in the Middle East. Cureus. 2020;12:e7520.

40. Liao Q, Yuan J, Dong M, Yang L, Richard F, Lam WT. Learning public engagement and government responsiveness in the communications about COVID-19 during the early epidemic stage in China: an analysis of social media data. J Med Internet Res. 2020. In press.

41. Corcoran B, Clarke A, Barrett T. Rapid response to HPV vaccination crisis in Ireland. Lancet. 2018;391(10135):2103. 
42. Aleem Z. New CDC data shows Covid-19 is affecting African Americans at exceptionally high rates. Vox. 2020. https://www.vox.com/coronavirus-covid19/2020/4/18/21226225/coronaviru s-black-cdc-infection.

43. Yancy CW. COVID-19 and African Americans. JAMA. 2020. In press. https://doi.org/10.1001/ jama.2020.6548.

44. Mheidly N, Fares J. Health communication in low-income countries: a 60-year bibliometric and thematic analysis. J Educ Health Promot. 2020;9:163.

Publisher's Note Springer Nature remains neutral with regard to jurisdictional claims in published maps and institutional affiliations.

Nour Mheidly MA, is a media and health communication researcher at the Lebanese University Faculty of Information, Beirut, Lebanon.

Jawad Fares MD, MSc, is a physician-scientist at Northwestern University Feinberg School of Medicine, Chicago, Illinois, USA. 